\title{
¿Impuesto a la Riqueza en el Perú? Reflexiones sobre su posible re-incorporación al Sistema Tributario Peruano
}

\section{Michael Fernando Morales Gamarra}

Abogado por la Universidad Peruana de Ciencias Aplicadas. Magíster en Docencia para la Educación Superior por la Universidad Andrés Bello de Chile. Postgrado en Derecho Tributario Internacional por la Universidad Austral de Buenos Aires. Profesor de Legislación Tributaria en la Universidad Peruana de Ciencias Aplicadas. Miembro del Instituto Peruano de Derecho Tributario. Miembro del International Fiscal Association.

Nataly Daniela Aspinwall Mejía

Abogada por la Universidad Peruana de Ciencias Aplicadas. Postgrado en Derecho Tributario Internacional por la Universidad Austral de Buenos Aires. Miembro del Instituto Peruano de Derecho Tributario. Miembro del International Fiscal Association.

SUMARIO:

I. Introducción.

II. El Impuesto al Patrimonio y la Riqueza.

III. Experiencia Comparada.

1. El impuesto a la riqueza en los países europeos miembros de la OCDE.

1.1. Suiza.

1.2. España.

1.3. Noruega.

2. El impuesto a la riqueza en Sudamérica.

2.1. Argentina.

2.2. Bolivia.

2.3. Colombia.

2.4. Uruguay.

3. Problemas presentados en la gestión del impuesto.

IV. El Impuesto a la riqueza en el Perú.

V. Análisis de las propuestas legislativas presentadas ante el Congreso de la República.

1. Proyecto de Ley $4887 / 2020$-CR.

2. Proyecto de Ley 5081/2020-CR.

3. Proyecto de Ley 5163/2020-CR.

4. Proyecto de Ley 6615/2020-CR.

5. Nuestros comentarios y/o apreciaciones sobre los proyectos presentados.

VI. Conclusiones. 


\title{
RESUMEN:
}

A través del presente artículo, los autores analizan la naturaleza del impuesto a la riqueza, su historia en el sistema tributario peruano, su aplicación en la legislación comparada así como diversas iniciativas legislativas presentadas en el Congreso de la República.

Palabras clave: Impuesto, patrimonio, riqueza, legislación comparada.

\begin{abstract}
:
In this article, the authors analyse the nature of the wealth tax, its history in the Peruvian tax system, how it has been applied in different jurisdictions and several legislative initiatives introduced to the Congress of Peru.

Keywords: Tax, estate, wealth, compared law.
\end{abstract}

\section{INTRODUCCIÓN}

Con motivo de la pandemia que afecta al mundo, causada por la enfermedad por coronavirus - COVID-19-, diversas jurisdicciones a nivel mundial se han visto obligadas a adoptar medidas sanitarias drásticas que han afectado e inclusive llevado al cierre de muchos establecimientos comerciales - debido a las medidas de cuarentena, por ejemplo-, lo cual ha devenido en una ola de suspensiones laborales, despidos masivos, disminución en el consumo interno, la producción de bienes y servicios, entre otros efectos adversos; lo cual a su vez ha generado la necesidad por parte de los Estados de otorgar subsidios a ciertos sectores a fin de no socavar enteramente sus economías.

De acuerdo con el Informe Anual del Fondo Monetario Internacional, correspondiente al año 2020', actualmente la economía mundial se encuentra atravesando una profunda recesión a consecuencia del impacto persistente de la COVID-19. Así, se tiene que la incertidumbre aún se cierne sobre las perspectivas económicas, y paralelamente actúan fuerzas de largo plazo que determinan e influyen en la respuesta de los países al virus y en la recuperación proyectada para los ejercicios siguientes.

En ese contexto, muchos países de Latinoamé- rica han visto la oportunidad ideal para aplicar o crear un impuesto dirigido a las personas con altos niveles patrimoniales -impuesto a la riqueza-.

Los argumentos planteados para el sustento de este tipo de imposiciones tributarias básicamente se encuentran en el nivel de inequidad que existe en la región en cuanto a la distribución de la riqueza y en la necesidad de obtener una mayor recaudación tributaria, toda vez que la emergencia sanitaria en la que se vive actualmente así lo ameritaría.

Sobre el particular, nuestro país no viene siendo ajeno a tal contexto regional, motivo por el cual se han presentado varios proyectos de ley en el Congreso de la República, los mismos que buscan gravar - a nivel de gobierno central- la riqueza de los ciudadanos.

En vista de lo anterior, el presente artículo ha sido redactado con el propósito de reflexionar sobre la conveniencia de reincorporar al sistema jurídico peruano un impuesto dirigido a gravar la riqueza de las personas; teniendo en cuenta que la gran mayoría de países avanzados en materia económica, ha renunciado a la aplicación de este tipo de gravámenes por los problemas que la gestión de los mismos implica y su ineficacia en términos de recaudación.

1. "Un año sin igual: Informe Anual del FMI de 2020", Fondo Monetario Internacional, acceso el 21 de marzo de 2021, https://www.imf.org/external/pubs/ft/ar/2020/eng/downloads/imf-annual-report-2020-es.pdf 


\section{EL IMPUESTO AL PATRIMONIO²}

Para efectos de entender el concepto de Impuesto al Patrimonio, primero resulta conveniente poder definir la palabra patrimonio.

Así, tenemos que, la palabra patrimonio proviene del latín patri, que significa "padre" y monium que significa "lo que recibo por línea paterna", siendo que el término posee distintas acepciones, tales como "la herencia que deja una persona a sus familiares" o "las propiedades que adquiere o puede adquirir una persona". ${ }^{3}$

Sobre el particular, la Real Academia Española de la Lengua ${ }^{4}$ define al término patrimonio como el "conjunto de bienes pertenecientes a una persona natural o jurídica, o afectos a un fin, susceptibles de estimación económica".

A decir de Diego Quiñones ${ }^{5}$, el Impuesto sobre el Patrimonio no resulta novedoso, toda vez que ha sido una figura utilizada, incluso, desde el periodo grecorromano clásico.

Sin embargo, no todo Impuesto al Patrimonio necesariamente implica un impuesto a la riqueza. ${ }^{6}$
Adina Luminita ${ }^{7}$ en relación con el Impuesto a la Riqueza señala que éste es un impuesto que grava mayormente la riqueza neta en cabeza de una persona o entidad. Por ejemplo, el monto de riqueza de un tercero menos sus acreencias. Así, muchos países alrededor del mundo usan este impuesto para recaudar fondos para el gobierno, usando varios tipos de bases imponibles.

Para Thurony $\mathrm{i}^{8}$, un Impuesto a la Riqueza neta puede distinguirse de un impuesto a la propiedad en el hecho en que el segundo grava el importe bruto del valor de una propiedad sin la reducción de la base - no se admiten deducciones- y usualmente son impuestos respecto de ciertos tipos de bienes; mientras que el Impuesto a la Riqueza se encuentra más relacionado a una base neta. Por ejemplo, el valor de una propiedad menos créditos.

Por otro lado, de acuerdo con la Tax Foundation', este tipo de impuestos gravan el valor de mercado de los activos totales, menos el valor de mercado de los pasivos totales, de propiedad de los hogares, siendo los impuestos sobre la propiedad, superficialmente similares a un impuesto sobre el patrimonio, sin restar los pasivos.

2. Existen diferencias conceptuales entre el impuesto al Patrimonio propiamente dicho y aquél que busca gravar la riqueza. Sin embargo, en el transcurso del artículo, salvo en este apartado; el término impuesto al Patrimonio será equivalente al de Impuesto a la Riqueza.

3. Margarita Melo Casas, Laura Pinilla Parra y Cristian Uribe Roa, "Impuesto a la riqueza: análisis crítico de su nacimiento, vigencia, efectividad y cumplimiento de los principios tributarios en Colombia." (tesis de grado, Universidad de Bogotá Jorge Tadeo Lozano, 2016).

4. "patrimonio", Real Academia Española, acceso el 21 de marzo de 2021, https://dle.rae.es/patrimonio

5. Diego Quiñones Cruz "El mito del eterno retorno: impuesto sobre el patrimonio en Colombia." Revista de Derecho Privado 42 (2009): 2-48: https://www.redalyc.org/articulo.oa?id=3600/360033191009

6. Como en el caso peruano el impuesto predial o vehicular.

7. Luminita Ristea y Adina Trandafir, "Wealth tax within Europe in the context of a possible implementation in Romania - The existing wealth tax and its decline in Europe", Annals of the University of Petrosani 10 (2010): 300.

8. Victor Thuronyi, Comparative Tax Law (Kluwer Law International, $1^{\circ}$ ed. 2003): 329.

9. Huaqun Li y Karl Smith, "Analysis of Sen. Warren and Sen. Sanders' Wealth Tax Plans", Tax Foundation, 28 de enero de 2020, acceso el 21 de marzo de 2021, https://taxfoundation.org/wealth-tax/\#Basics 
Otra de las características propias de este tipo de impuestos es el referente a sus exclusiones. De acuerdo con la Dirección de Estudios e Investigaciones Tributarias del Centro Interamericano de Administraciones Tributarias - $\mathrm{CIAT}^{10}$, no existe Impuesto a la Riqueza que no contenga exclusiones o excepciones, siendo las más frecuentes las de la vivienda habitual, activos financieros públicos, ciertos elementos de ahorro previsional o el ajuar doméstico. Asimismo, se señala que un mínimo imponible es imprescindible para que el impuesto sea operativo.

A pesar de que existen diferencias entre un impuesto que grava el patrimonio respecto de uno que grava la riqueza de los individuos, en los siguientes párrafos y en lo que resta del artículo, nos referiremos a ambos términos de manera equivalente.

Ahora bien, de acuerdo con el Proyecto de Ley que implementó el Impuesto al Patrimonio en España, los objetivos primordiales de éste son: (i) la búsqueda de una mayor equidad en la carga tributaria; (ii) el fomento de un uso más productivo del patrimonio; (iii) el que el impuesto sirva como complemento del impuesto a la renta; $y_{\text {, (iv) que }}$ se genere un efecto redistribuidor de riqueza. ${ }^{11}$

En efecto, el caso español refleja lo que los Estados típicamente buscan con la imposición de este tipo de gravámenes, lo cual es principal- mente generar un efecto redistribuidor en la riqueza.

Así, por ejemplo, Diego Quiñones ${ }^{12}$ señala, al analizar el caso colombiano, que la función que cumplen este tipo de impuestos es básicamente: (i) equitativa — vertical- redistributiva; (ii) recaudatoria; (iii) de control y complemento dentro del sistema tributario; $y$, (iv) productista.

A decir de Pablos ${ }^{13}$, este tipo de imposiciones encuentra su fundamento en temas relacionados con la equidad, la distribución de la renta y riqueza, y una de sus principales defensas es la creencia de que, en sí mismo, el patrimonio - riqueza - es un índice de capacidad de pago y, como tal, ha de ser gravado. Por otro lado, quienes se oponen al tributo señalan que existe una escasa recaudación, produce efectos de desincentivo sobre el trabajo, ahorro e inversión.

No obstante lo loable de los fines buscados con este tipo de tributos, la experiencia internacional ha mostrado dificultades a la hora de gravar el patrimonio. Dificultades que encuentran su origen en la valuación de los activos, actualización de los mínimos imponibles, sistemas de control y fiscalización, entre otros. Ello, aunado a la baja recaudación que su existencia implicaba, hizo que los tributos al patrimonio hayan caído en desuso. ${ }^{14}$

10. Juan Carlos Benites y Fernando Velayos, Impuestos a la Riqueza o al Patrimonio de las Personas Físicas con especial mención a América Latina y El Caribe, (Centro Interamericano de Administraciones Tributarias, 2018): 23 y 44 .

11. Carlos Martínez Sánchez, "La imposición sobre el patrimonio como instrumento para una distribución equitativa de la riqueza", Estudios de Progreso 58 (2011).

12. Diego Quiñones, Op. Cit. p. 21.

13. Laura De Pablos Escobar, "Alternativas a la Supresión del Impuesto sobre el Patrimonio", Documentos de Trabajo 2009-006 6.

14. Sergio Paez y Guillermo Oglietti, “¿Cuánto podría recaudar el impuesto a las grandes fortunas en América Latina?", celag.org, 01 de junio de 2020, acceso el 21 de marzo de 2021, https://www.celag.org/cuanto-podria-recaudar-el-impuesto-a-las-grandes-fortunas-en-america-latina/

15. OECD, "The Role and Design of Net Wealth Taxes in the OECD", OECD Tax Policy Studies 26 (2018), https://doi.org/10.1787/9789264290303-en. 
Efectivamente, de acuerdo con la Organización para la Cooperación y el Desarrollo Económicos $-\mathrm{OCDE}^{15}$, actualmente el Impuesto sobre el Patrimonio neto está mucho menos extendido de lo que solía estar en la OCDE, siendo que las decisiones relacionadas con su extinción encuentran lugar en el hecho de que existían problemas relacionados con la eficacia esperada con relación a una mejora en las metas redistributivas. Así, los ingresos recaudados por este impuesto generalmente han sido muy bajos.

\section{EXPERIENCIA COMPARADA}

Esta sección del artículo tiene como objeto servir como apoyo al debate público, considerando la experiencia internacional comparada en la aplicación del Impuesto a la Riqueza.

A continuación, describiremos las características principales del Impuesto a la Riqueza vigente en siete países - tres países europeos y cuatro sudamericanos-; y mostraremos los efectos de este impuesto en la recaudación de cada uno de esos países.
1. El impuesto a la riqueza en los países europeos miembros de la OCDE.

La OCDE recomienda la implementación del impuesto sobre el patrimonio neto únicamente cuando no se ha implementado un impuesto sobre las ganancias y activos y/o cuando las tasas de estos sean bajas. Aún así, la OCDE recomienda que antes de su implementación se analice la interacción de este con el actual sistema tributario de cada país, cuidando que la carga tributaria total no sea excesiva.

Para tales efectos, la OCDE recomienda excluir del ámbito de aplicación del Impuesto a la Riqueza a los bienes destinados al comercio o al ejercicio profesional, los bienes de uso personal y/o domésticos, permitir la deducción de deudas para adquirir los activos, establecer normas para prevenir la doble tributación internacional sobre la riqueza, entre otros aspectos. ${ }^{16}$

Teniendo en cuenta ello, debemos precisar que los países europeos miembros de la OCDE que han implementado el Impuesto a la Riqueza lo mantengan vigente o no- son los siguientes:

TABLA 1: Comparación países europeos miembros de la OCDE ${ }^{17}$

\begin{tabular}{|c|c|c|c|}
\hline País & Año de establecimiento & Estado actual & Detalle impositivo \\
\hline Alemania & 1952 & Derogado & $1.0 \%$ \\
\hline Austria & 1954 & Derogado & $1.0 \%$ \\
\hline Dinamarca & 1903 & Derogado & Sin información \\
\hline Finlandia & 1919 & Derogado & $0.8 \%$ \\
\hline Francia & 1982 & Derogado & $0.5 \%-1.5 \%$ \\
\hline Holanda & 1965 & Derogado & $0.7 \%$ \\
\hline Irlanda & 1975 & Derogado & $1.0 \%$ \\
\hline Luxemburgo & 1934 & Derogado & $0.5 \%$ \\
\hline Suecia & 1947 & Derogado & $1.5 \%$ \\
\hline Islandia & 1970 & Derogado & $1.5 \%$ \\
\hline Suiza & 1840 & Vigente & $0.05 \%-0.5 \%$ \\
\hline España & 1977 & Vigente & $0.2-2.5 \%$ \\
\hline Noruega & 1892 & Vigente & $0.85 \%$ \\
\hline
\end{tabular}

16. Juan Pablo Cavada Herrera y Pablo Morales, Impuesto a los altos patrimonios personales - Legislación y experiencia extranjera (Santiago: Biblioteca del Congreso Nacional de Chile | Asesoría Técnica Parlamentaria, 2020), 1.

17. En el continente europeo impuestos similares han sido implementados en Bélgica, Francia, Países Bajos e Italia. Sin embargo, la configuración de los mismos no es propia de un Impuesto a la Riqueza, motivo por el cual no han sido considerados en el cuadro. 
De este cuadro, se puede concluir que la mayoría de los países OCDE que implementaron este impuesto, con el tiempo, han decidido derogarlo, estando vigente al día de hoy únicamente en tres países, los mismos que a continuación pasaremos a desarrollar.

\subsection{Suiza. ${ }^{18}$}

En Suiza, todos los cantones ${ }^{19}$ han implementado un Impuesto sobre el Patrimonio neto, el cual se calcula sobre la base del importe resultante de la diferencia entre el saldo de los activos brutos mundiales menos las deudas - por ejemplo, hipotecas o préstamos-, las cuales resultan ser deducibles sin límites aplicables. En ciertos cantones, se permiten deducciones adicionales en función al concepto.

Cabe mencionar que, entre los activos a reportar ante la Administración Tributaria Suiza se encuentran los siguientes:

a) Saldos de las cuentas bancarias, bonos, acciones, fondos y otros.

b) Seguros de vida con un valor de rescate.

c) Coches, barcos, aviones, entre otros. d) Propiedades inmobiliarias.

e) Otros activos de valor; estos son, pinturas, colecciones de arte, joyas, entre otros.

Los bienes de uso domésticos no se encuentran sujetos al impuesto.

Finalmente, las tasas aplicables van desde $0.15 \%$ hasta $1.01 \%$ dependiendo del cantón. Asimismo, se hacen diferencias -en relación con la franja impositiva - entre si el contribuyente es soltero, casado, o posee otra condición en particular.

\subsection{España. ${ }^{20}$}

En España, el Impuesto sobre el Patrimonio es un tributo de carácter directo y naturaleza personal que grava el patrimonio neto de las personas físicas. Este impuesto grava todos los activos mantenidos por los contribuyentes al 31 de diciembre de cada ejercicio.

El impuesto se determina aplicando la tasa establecida por la Comunidad Autónoma. En caso la Comunidad Autónoma no hubiese aprobado una tasa a aplicar, el impuesto se calculará aplicando la siguiente escala progresiva:

TABLA 2: Escala Progresiva Acumulativa

\begin{tabular}{c|c|c|c}
$\begin{array}{c}\text { Base imponible } \\
\text { (hasta EUR) }\end{array}$ & $\begin{array}{c}\text { Cuota } \\
\text { (Euros) }\end{array}$ & $\begin{array}{c}\text { Resto de base imponible } \\
\text { (hasta EUR) }\end{array}$ & $\begin{array}{c}\text { Tasa aplicable } \\
\text { (\%) }\end{array}$ \\
\hline 0.00 & 0.00 & $167,129.45$ & 0.2 \\
\hline $167,129.45$ & 334.26 & $167,123.43$ & 0.3 \\
\hline $334,252.88$ & 835.63 & $334,246.87$ & 0.5 \\
\hline $668,499.75$ & $2,506.86$ & $668,499.76$ & 0.9 \\
\hline $1,336,999.51$ & $8,523.36$ & $1,336,999.50$ & 1.3 \\
\hline $2,673,999.01$ & $25,904.35$ & $2,673,999.02$ & 1.7 \\
\hline $5,347,998.03$ & $71,362.33$ & $5,347,998.03$ & 2.1 \\
\hline $10,695,996.06$ & $183,670.29$ & en adelante & 2.5
\end{tabular}

18. "Worldwide Tax Summaries - Switzerland", en PWC, 27 de enero de 2021, acceso 21 de marzo de 2021, https:// taxsummaries.pwc.com/switzerland/individual/other-taxes

19. Los cantones constituyen los entes administrativos y políticos sobre los que se ha constituido el Estado Suizo.

20. "Worldwide Tax Summaries - Spain", en PWC, 27 de enero de 2021, acceso 21 de marzo de 2021, https://taxsummaries.pwc.com/spain/individual/other-taxes 
Cabe mencionar que, la base imponible se reducirá - mínimo exento- en el importe que haya sido aprobado por la Comunidad Autónoma. En caso la Comunidad Autónoma no haya regulado el mínimo exento, la base imponible se reducirá en EUR 700,000.21

Como se puede observar, las Comunidades Autónomas cuentan con la posibilidad de establecer su propia reducción a la base imponible del impuesto; así como las tasas a aplicar para la determinación de este.

\subsection{Noruega. ${ }^{22}$}

En Noruega, se implementó el Impuesto sobre el Patrimonio a nivel municipal y estatal; lo que significa que las personas naturales pagan un impuesto municipal y otro estatal sobre el patrimonio.

Estos impuestos se calculan de la siguiente manera:

a) El impuesto municipal sobre el patrimonio se determinará aplicando un $0.7 \%$ sobre la base de activos que exceden una base neta del impuesto sobre el capital de 1.5 millones de coronas noruegas - NOK- ${ }^{23}$ para los contribuyentes solteros y de $3 \mathrm{mi}$ llones de $\mathrm{NOK}^{24}$ para las parejas casadas.

b) El impuesto estatal sobre el patrimonio se calculará aplicando una tasa de $0.15 \%$ sobre la base de activos que exceden una base neta del impuesto sobre el capital de
1.5 millones de NOK para los contribuyentes casados y de 3 millones de NOK para las parejas casadas.

Finalmente, se debe advertir que la tasa máxima del impuesto será del $0.85 \%$.

\section{El impuesto a la riqueza en Sudamérica.}

En Sudamérica el impuesto se encuentra vigente en Argentina, Bolivia, Colombia, Uruguay y Venezuela.

En Chile, con fecha 1 de junio del 2020, se ha presentado un Proyecto de Reforma Constitucional a fin de establecer por única vez un Impuesto al Patrimonio de personas que cuenten con altos patrimonios.

En Ecuador se creó, en el ejercicio 2016, por única vez, una Contribución Solidaria sobre el patrimonio que gravó aquellos patrimonios mayores a USD 1 millón con una tasa del $0.90 \%$.

A continuación, pasaremos a observar las características que posee este impuesto respecto de los países en los que se encuentra vigente -excepto Venezuela-:

\subsection{Argentina. ${ }^{25}$}

En diciembre de 2020, se creó ${ }^{6}$ con carácter de emergencia y por única vez, un aporte extraordinario sobre grandes fortunas, también conocido como el Impuesto a la Riqueza.

21. Artículo 28 de la Ley 19/1991.

22. "Worldwide Tax Summaries - Norway", en PwC, 06 de febrero de 2021, acceso 21 de marzo de 2021, https://taxsummaries.pwc.com/norway

23. Aproximadamente USD 175,600.00 a la fecha de la edición de este artículo —21 de marzo de 2021—.

24. Aproximadamente USD 351,200.00 a la fecha de la edición de este artículo —21 de marzo de 2021—.

25. En el caso particular de Argentina, adicionalmente, desde el año 1991 existe el impuesto a los activos personales cuyas características son propias de un Impuesto a la Propiedad.

26. A través de la Ley 27605. 
Para tales efectos, la base imponible está dada por los aportes a trusts, fideicomisos o fundaciones de interés privado y demás estructuras análogas, participación en sociedades u otros entes de cualquier tipo sin personalidad fiscal y participación directa o indirecta en sociedades u otros entes de cualquier tipo, existentes. ${ }^{27}$

Teniendo en cuenta ello, el importe a cancelar por parte de los contribuyentes es el que resulte de aplicar, sobre el valor total de los bienes, la siguiente escala ${ }^{28}$ :

TABLA 3: Escala Progresiva Acumulativa

\begin{tabular}{|c|c|c|c|c|}
\hline \multicolumn{2}{|c|}{ Valor Total de los bienes } & \multirow{2}{*}{ Pagarán } & \multirow{2}{*}{ Más el } & \multirow{2}{*}{$\begin{array}{l}\text { Sobre el } \\
\text { excedente } \\
\text { de ARS }\end{array}$} \\
\hline más de $\operatorname{ARS}^{29}$ & a ARS & & & \\
\hline ARS 0 & $\begin{array}{l}\text { ARS 300,000,000 } \\
\text { inclusive }\end{array}$ & ARS 0 & $2.00 \%$ & ARS 0 \\
\hline ARS $300,000,000$ & $\begin{array}{l}\text { ARS } 400,000,000 \\
\text { inclusive }\end{array}$ & ARS $6,000,000$ & $2.25 \%$ & ARS $300,000,000$ \\
\hline ARS $400,000,000$ & $\begin{array}{l}\text { ARS 600,000,000 } \\
\text { inclusive }\end{array}$ & ARS $8,250,000$ & $2.50 \%$ & ARS $400,000,000$ \\
\hline ARS $600,000,000$ & $\begin{array}{l}\text { ARS } 800,000,000 \\
\text { inclusive }\end{array}$ & ARS $13,250,000$ & $2.75 \%$ & ARS $600,000,000$ \\
\hline ARS $800,000,000$ & $\begin{array}{c}\text { ARS } 1,500,000,000 \\
\text { inclusive }\end{array}$ & ARS $18,750,000$ & $3.00 \%$ & ARS $800,000,000$ \\
\hline ARS $1,500,000,000$ & $\begin{array}{c}\text { ARS } 3,000,000,000 \\
\text { inclusive }\end{array}$ & ARS $39,750,000$ & $3.25 \%$ & ARS $1,500,000,000$ \\
\hline ARS $3,000,000,000$ & en adelante & ARS $88,500,000$ & $3.50 \%$ & ARS $3,000,000,000$ \\
\hline
\end{tabular}

Adicionalmente, se establece que por los bienes situados en el exterior se deberá calcular el aporte a ingresar conforme a la siguiente tabla:

TABLA 4: Escala Progresiva Acumulativa por bienes del exterior

\begin{tabular}{c|c|c}
\hline \multicolumn{2}{|c|}{ Valor total de los bienes del país y del exterior } & $\begin{array}{c}\text { Por el total de los bienes } \\
\text { situados en el exterior, } \\
\text { pagarán el }\end{array}$ \\
más de ARS & a ARS & $3.00 \%$ \\
\hline ARS $200,000,000$ & ARS $300,000,000$ inclusive & $3.375 \%$ \\
\hline ARS $300,000,000$ & ARS $400,000,000$ inclusive & $3.75 \%$ \\
\hline ARS 400,000,000 & ARS $600,000,000$ inclusive & $4.125 \%$ \\
\hline ARS $600,000,000$ & ARS $800,000,000$ inclusive & $4.50 \%$ \\
\hline ARS $800,000,000$ & ARS $1,500,000,000$ inclusive & $4.875 \%$ \\
\hline ARS $1,500,000,000$ & ARS 3,000,000,000 inclusive & $5.25 \%$ \\
\hline ARS 3,000,000,000 & en adelante & $\vdots$ \\
\hline
\end{tabular}

27. Artículo 3 de la Ley 27605.

28. Artículo 4 de la Ley 27605.

29. Para efectos referenciales, ARS 100,000.00 equivalen aproximadamente a USD 1,099.00 a la fecha de la edición de este artículo -21 de marzo de 2021-. 
Como se señaló anteriormente, este impuesto fue creado de manera excepcional, por lo que su aplicación fue por única vez.

\subsection{Bolivia.}

Con fecha 28 de diciembre de 2020, se creó el Impuesto a las Grandes Fortunas - IGF, el cual se aplica al patrimonio de las personas naturales. Para tales efectos, el patrimonio gravable de las personas naturales es el comprendido por los bienes inmuebles, bienes muebles, bienes suntuarios, activos financieros, derechos, dinero y todo otro bien material o inmaterial con valor económico, de los cuales sea titular el contribuyente o cuando esté en posesión de estos. ${ }^{30}$

Cabe mencionar que la hipótesis de incidencia del impuesto se perfeccionará cuando el patrimonio neto acumulado al 31 de diciembre de cada año, de los sujetos pasivos, sea mayor a los BOB $30,000,000.00^{31}$ o su equivalente en moneda extranjera. ${ }^{32}$

Finalmente, debemos mencionar que para determinar el IGF, la base imponible estará constituida por el valor neto del patrimonio, el cual es el resultado de la sumatoria de todo el patrimonio acumulado menos los saldos de capital pendientes de pago por préstamos obtenidos de entidades financieras reguladas por la Autoridad de Supervisión del Sistema Financiero. Sobre dicha base imponible se aplica progresivamente la siguiente escala de alícuotas ${ }^{33}$ :
TABLA 5: Escala Progresiva Acumulativa

\begin{tabular}{|c|c|}
\hline Base imponible en BOB & Alícuota \\
\hline $30,000,001$ a 40,000,000 & $1.4 \%$ \\
\hline $40,000,001$ a $50,000,000$ & $1.9 \%$ \\
\hline $50,000,001$ en adelante & $2.4 \%$ \\
\hline
\end{tabular}

\subsection{Colombia.}

Actualmente, de acuerdo con la Ley 2010, el Impuesto al Patrimonio tendrá una vigencia hasta el presente ejercicio —2021—. ${ }^{34}$

Este Impuesto al Patrimonio tiene las siguientes características:

a) Sujetos pasivos:

El impuesto recae sobre ${ }^{35}$ :

(i) Las personas naturales;

(ii) Las sucesiones ilíquidas;

(iii) Los contribuyentes del impuesto sobre la renta y complementarios o de regímenes sustitutivos del impuesto sobre la renta; $y$,

(iv) Las sociedades o entidades extranjeras que no sean declarantes del impuesto sobre la renta en el país, y que posean bienes ubicados en Colombia diferentes a acciones, cuentas por cobrar y/o inversiones de portafolio.

b) Hecho generador:

El hecho generador del impuesto es la pose-

30. Artículo 1 de la Ley 1357.

31. Aproximadamente USD 4,346,000.00 a la fecha de edición del presente artículo —21 de marzo de 2021—.

32. Artículo 5 de la Ley 1357.

33. Artículos 7 y 9 de la Ley 1357.

34. Anteriormente, mediante Ley 1739 el impuesto había tenido una aplicación temporal por los ejercicios 2015 al 2018, siendo que esta abarca los ejercicios 2019, 2020 y 2021.

35. Artículo 292-2 del Estatuto Tributario. 
sión al 01 de enero del 2021 de un patrimonio, cuyo valor sea igual o superior a cinco mil millones de pesos. ${ }^{36}$ Para tales efectos, el concepto de patrimonio es equivalente al patrimonio líquido, calculado considerando el total del patrimonio bruto menos las deudas vigentes a esa fecha. ${ }^{37}$

c) Base imponible:

La base gravable del impuesto al patrimonio es el valor del patrimonio bruto de los sujetos pasivos poseído al 01 de enero de 2021 menos las deudas a cargo de estos, vigentes en esas mismas fechas. ${ }^{38}$

d) Tasas del impuesto:

La tasa del impuesto es del $1 \%$ por cada año, del total de la base gravable antes descrita. ${ }^{39}$

\subsection{Uruguay. ${ }^{40}$}

El Impuesto al Patrimonio se aplica a los contribuyentes al final de cada año calendario y en una escala móvil de tasas que dependerá del estado de residencia de la persona.

Las personas naturales residentes tienen una tasa que va desde el $0.3 \%$ al $0.6 \%$, en tanto que los no residentes tienen una tasa que va desde el $0.7 \%$ al $1.5 \%$.

Uruguay aplica el impuesto únicamente a los activos ubicados o utilizados económicamente en su territorio.

Actualmente, el mínimo exento aplicable al impuesto asciende a la suma de UYU 4,491,000. ${ }^{41}$

\section{Problemas presentados en la gestión del impuesto.}

Como hemos podido observar en los párrafos precedentes, la gran mayoría de países europeos miembros de la OCDE que, en su oportunidad, decidieron implementar el Impuesto a la Riqueza como parte de su sistema tributario nacional, actualmente lo han derogado.

Ello se debe a los diversos problemas que existen en el diseño, implementación y control de este tipo de impuestos, entre los cuales podemos mencionar los siguientes:

a) Fuga de capitales: la implementación del Impuesto a la Riqueza puede generar efectos nocivos sobre la economía de un país, por cuanto podría generar una fuga de capitales porque este tipo de impuesto castiga a los ahorradores.

Para César Martíne ${ }^{42}$, esta afirmación debe ser matizada, teniendo presente que este tipo de impuesto grava tanto bienes muebles como inmuebles, de los cuales respecto a los inmuebles no podría alegarse ningún tipo de fuga de capitales; sin embargo, ello no podría afirmarse respecto de los bie-

36. Aproximadamente USD 1,415,000.00 a la fecha de edición del presente artículo —21 de marzo de 2021—.

37. Artículo 294-2 del Estatuto Tributario.

38. Artículo 295-2 del Estatuto Tributario.

39. Artículo 296-2 del Estatuto Tributario.

40. "Worldwide Tax Summaries - Uruguay", en PwC, 05 de enero de 2021, acceso 21 de marzo de 2021, https://taxsummaries.pwc.com/uruguay/individual/other-taxes

41. Aproximadamente USD 101,000.00 a la fecha de edición del presente artículo —21 de marzo de 2021—.

42. César Martínez, “¿Tiene sentido que exista un impuesto sobre la riqueza?" Razón y Fe 277, 143, (2018): 8. 
nes muebles. No obstante, no compartimos esta afirmación, toda vez que, en el caso de los bienes inmuebles, la fuga del capital tendrá lugar con motivo de la enajenación o abandono del inmueble.

Adicionalmente, el autor señala que, se puede advertir que otra forma en la que los sujetos no califiquen como contribuyentes del Impuesto a la Riqueza sería dejar de calificar como un sujeto domiciliado del Estado, dándose así también la famosa fuga de capitales.

b) Dificultades en la valoración de los activos: actualizar el valor de mercado de los activos que forman parte de la base imponible de este impuesto no resulta ser una tarea fácili. ${ }^{43}$

Ello no sólo se encuentra relacionado con el establecimiento de los diferentes métodos de valoración para cada uno de los activos que forman parte de la base imponible, sino que al existir activos gravados con el impuesto que no se encuentran dentro del territorio, resulta difícil conseguir la base de datos para la aplicación de estos métodos de valoración. Esto sin tomar en cuenta los problemas inherentes a la valoración de bienes o derechos que no cotizan en un determinado mercado. c) Altos costos de gestión y control: como lo hemos indicado anteriormente, este impuesto grava los bienes muebles ubicados en el exterior, lo cual genera altas dificultades al momento de verificar su efectiva tributación.

La solución a esta problemática podría estar avanzando con los famosos acuerdos de intercambio de información tributaria suscritos entre los Estados - por ejemplo, la reciente suscripción por parte del Perú de la Convención sobre Asistencia Administrativa Mutua en Materia Tributaria, en el marco de la OCDE-. ${ }^{44}$

De esta manera, pese a los esfuerzos por reducir los costos de gestión y control de este impuesto, la complejidad de éste y la falta de claridad en su entorno trae como consecuencia que se requiera de un gran número de funcionarios para realizar las verificaciones de una correcta tributación.

d) Baja recaudación: está demostrado que la recaudación obtenida por el Impuesto a la Riqueza resulta ser irrelevante en la recaudación total de los que hemos venido analizando. Ello se puede acreditar con la siguiente tabla:

TABLA 6: Nivel de recaudación

\begin{tabular}{|c|c|c|c|c|}
\hline \multirow[b]{2}{*}{ Países } & \multicolumn{2}{|c|}{2017} & \multicolumn{2}{|c|}{2018} \\
\hline & $\begin{array}{c}\text { Total } \\
\text { recaudación }\end{array}$ & $\begin{array}{c}\% \text { de recaudación } \\
\text { del Impuesto al } \\
\text { patrimonio }\end{array}$ & $\begin{array}{l}\text { Total } \\
\text { recaudación }\end{array}$ & $\begin{array}{c}\text { \% de recaudación } \\
\text { del Impuesto al } \\
\text { patrimonio }\end{array}$ \\
\hline Suiza & 191,119 & 3.83 & 194,391 & 3.81 \\
\hline España & 393,529 & 0.53 & 416,692 & 0.52 \\
\hline Noruega & $1,277,949$ & 1.21 & $1,397,206$ & 1.13 \\
\hline Argentina & $3,202,629$ & 0.69 & $4,203,894$ & 0.34 \\
\hline Bolivia & 67,072 & 0 & 70,634 & 0 \\
\hline Colombia & $174,735,823$ & 2.21 & $190,299,911$ & 0.24 \\
\hline Uruguay & 494,580 & 0.14 & 534,208 & 0.14 \\
\hline
\end{tabular}

43. Alexander Krenek y Margit Schratzenstaller. “Sustainability-oriented Future EU. Funding: A European Net Wealth Tax", Fairtax Working Paper Series 10 (2017): 13

44. César Martínez, Op. Cit., 9. 
Como se puede observar, existe una serie de problemas en el diseño, implementación y control en el Impuesto a la Riqueza, lo cual originó que la mayoría de los países europeos - que en su oportunidad decidieron implementarlo en su sistema tributario- eliminaran dicho impuesto.

Finalmente, no existe prueba empírica en la experiencia comparada que demuestre contundentemente que la imposición de este tipo de tributos genere un impacto sustancial en la lucha contra la inequidad en términos de distribución de la riqueza. Más aún, se encuentra acreditado que el impacto de su recaudación no es material.

\section{EL IMPUESTO A LA RIQUEZA EN EL PERÚ}

A través del Decreto Ley 19654 del 12 de diciembre de 1972, el entonces Gobierno Revolucionario del General Juan Velasco Alvarado reestructuró el sistema tributario, vigente en ese entonces, creando el Impuesto al Patrimonio Empresarial ${ }^{45}$, el cual gravaba el patrimonio neto de las empresas con una tasa progresiva que iba -inicialmente- desde el $0.6 \%$ al $1.20 \%$. El impuesto establecido tenía una periodicidad anual y era pagado, originalmente, en 4 cuotas y su base imponible se calculaba a partir del exceso de $S / .1,000,001.00 .{ }^{46}$

A decir de Hernández ${ }^{47}$, este impuesto tiene como antecedente inmediato al Impuesto al Patrimonio Accionario, que gravaba el patrimonio de las sociedades por acciones y de las sucursales de empresas extranjeras. Como podemos observar, ese impuesto únicamente gravaba el patrimonio de las personas jurídicas mas no de las naturales. ${ }^{48}$

Por otro lado, a través del Decreto Legislativo 451, promulgado el 30 de diciembre de $1987^{49}$, se creó el "Impuesto que grava al patrimonio neto de las personas naturales y sucesiones indivisas"; teniéndose así ya este gravamen afectando el patrimonio de las personas naturales. Las disposiciones reglamentarias del presente Decreto estuvieron dadas por el Decreto Supremo No 176-88-EF.

El tributo referido anteriormente gravaba básicamente los patrimonios netos ${ }^{50}$ de las personas naturales y sucesiones indivisas cuyo valor computable hubiera excedido las doscientas Unidades Impositivas Tributarias UIT. La tasa aplicable al impuesto era una de carácter progresiva acumulativa que llegaba hasta el $3 \% .^{51}$

Posteriormente, se emitió el Decreto Legislativo 620, promulgado el 29 de noviembre de $1990 .^{52}$ El presente decreto sustituyó el régimen vigente para personas naturales y sucesiones indivisas establecido a través del Decreto Legislativo 451;

45. Vigente desde el 1 de enero de 1973.

46. Soles de Oro de la época.

47. Luis Hernández Berenguel, “El impuesto a los Activos", IUS ET VERITAS 3 (1991): 41

48. De acuerdo con el artículo 3 del Decreto Ley 19654 se entendía como empresas a las personas naturales, sucesiones indivisas y personas jurídicas que se dediquen a alguna actividad lucrativa de extracción, producción, comercio o servicios industriales, comerciales y similares; con excepción de las asociaciones y fundaciones por actividades lucrativas que realicen para el cumplimiento de sus fines.

49. Vigente desde el 1 de enero de 1988.

50. Entendidos estos - de acuerdo con el artículo 1 del Decreto Legislativo 451 - como la diferencia entre los bienes ubicados territorialmente en el país y las deudas en el país computables al cierre del ejercicio.

51. Ver artículo 7 del Decreto Legislativo 451.

52. Vigente desde el 1 de enero de 1991. 
incorporando como sujetos pasivos a las sociedades conyugales.

Asimismo, el nuevo régimen establecía que el patrimonio afecto era aquel constituido únicamente por predios, vehículos automotores, aeronaves, embarcaciones de recreo y deportivas, créditos en moneda nacional o extranjera otorgados a personas naturales, entre otros; en tanto el valor total del patrimonio exceda la suma de 10 UIT correspondientes al mes de enero de cada año y únicamente por dicho exceso.

Estos regímenes no tuvieron mucho tiempo de vigencia, toda vez que fueron derogados a través de la Primera Disposición Transitoria del Decreto Ley 25988. Sobre este punto cabe indicar que de acuerdo con Jorge Bravo Cucci53, las bases normativas de nuestro actual sistema tributario se sustentan en la reforma llevada a cabo a inicios de 1990 cuando se derogó una exorbitante cantidad de tributos ineficientes y de baja recaudación que distraían y complicaban la labor de la Administración Tributaria sin generar mayores recursos para el Estado.

Al día de hoy, las personas naturales se encuentran afectas a impuestos que gravan su patrimonio sólo a nivel municipal, a través de la aplicación del impuesto vehicular o del impuesto predial, no existiendo un impuesto que grave el patrimonio ni la riqueza a nivel de gobierno central.

\section{ANÁLISIS DE LAS PROPUESTAS LEGISLA- TIVAS PRESENTADAS}

Como lo mencionamos anteriormente, actualmente en el Perú existen 4 proyectos de ley que buscan la reincorporación del Impuesto a la $\mathrm{Ri}$ queza en el sistema tributario vigente.
En el presente apartado, pasaremos a ver las principales características de cada proyecto de ley presentado ante el Congreso de la República y cuyos debates aún no han sido agendados ${ }^{54}$ :

\section{Proyecto de Ley $4887 / 2020-C R .{ }^{55}$}

a) Denominación: Impuesto Solidario a las Grandes Fortunas.

b) Contribuyentes ${ }^{56}$ :

(i) Personas naturales que hayan obtenido durante el año ingresos a partir de $S / 1,000,000.00$ o que los montos de sus inmuebles asciendan a dicha suma.

(ii) Personas jurídicas que hayan facturado durante el año fiscal ingresos a partir de $S / 10,000,000.00$ o que su patrimonio inmobiliario posea en libros tal monto.

(iii) Grupos económicos que hayan facturado durante el año fiscal ingresos a partir de $S / 50,000,000.00$ o que su patrimonio inmobiliario posea en libros tal monto.

c) Tasa aplicable:

(i) Personas naturales: de $0.22 \%$ a $1 \%$.

(ii) Personas jurídicas: de $1 \%$ a $2 \%$.

(iii) Grupos económicos: de 2\% a 3\%.

d) Base Imponible:

(i) Personas naturales: ingresos obtenidos durante el ejercicio o valor de sus inmuebles.

(ii) Personas jurídicas: facturación o valor en libros de sus inmuebles.

53. Jorge Bravo Cucci, "Sistema Tributario Peruano: Situación Actual y Perspectivas", Derecho y Sociedad 27 (2006): 86.

54. Nota del Editor: a la fecha de edición del presente artículo, 21 de marzo de 2021, todos los proyectos aquí desarrollados aún permanecen en Comisión.

55. Presentado el 24 de marzo del 2020.

56. Proyecto no distingue si el aspecto subjetivo únicamente se circunscribe a los sujetos domiciliados en el país. 
(iii) Grupos económicos: facturación o valor en libros de sus inmuebles.

e) Aspecto Territorial: no indica si se trata de ingresos de fuente peruana o mundial. Igualmente, el proyecto no señala si sólo se encontrarán gravados los inmuebles ubicados en territorio nacional. Sin embargo, al señalar que el valor considerado es el que consta en los libros, da a entender que se trata de inmuebles ubicados en territorio de la República.

f) Aspecto Temporal: permanente.

g) Exposición de Motivos:

(i) El artículo 61 de la Constitución Política del Perú no ha cumplido su cometido, toda vez que existen fallas en el reparto de nuestra riqueza.

(ii) Los impuestos en el Perú son únicamente indirectos, por lo que corresponde al Estado dotarse de mayores ingresos a través de este gravamen.

\section{Proyecto de Ley $5081 / 2020-C R .{ }^{57}$}

a) Denominación: Ley de Impuesto a las Ganancias.

b) Contribuyentes ${ }^{58}$ : personas naturales y jurídicas cuyas ganancias durante el ejercicio sean mayores a $S / 10,000,000.00$.

c) Tasas aplicables:

\begin{tabular}{|c|c|c}
\multicolumn{2}{c|}{ Ganancia imponible } & Tasa \\
\hline Más de S/ & A S/ & $\%$ \\
\hline 10 millones & 50 millones & 1 \\
\hline 51 millones & 1 mil millones & 2 \\
\hline 1 mil millones & A más & 3 \\
\hline
\end{tabular}

d) Base Imponible: total de utilidades netas, rentas y enriquecimientos susceptibles de una periodicidad que implique la permanencia de la fuente que los produce. Asimismo, se incluyen los beneficios obtenidos por la enajenación de bienes; que, para estos efectos es la venta, permuta, cambio, expropiación, aporte a sociedades y, en general, todo acto de disposición por el que se transmite el dominio a título oneroso.

e) Aspecto Territorial: proyecto no señala tratamiento diferenciado para ganancias obtenidas de fuente extranjera.

f) Aspecto Temporal: únicamente por los ejercicios 2020 y 2021.

g) Exposición de Motivos:

(i) En el Perú existe una alta concentración de la riqueza.

(ii) El impuesto a las ganancias se justifica en que, uno de los objetivos centrales de la política fiscal de los Estados es la redistribución equitativa de la riqueza y el acceso justo a la distribución del ingreso.

(iii) La carga del impuesto a la renta en promedio es del $1.4 \%$ frente al $8.4 \%$ de los países miembros de la OCDE.

El proyecto dispone adicionalmente la creación de un bono universal en periodos de emergencia sanitaria, el mismo que sería otorgado a todo ciudadano peruano que viva en condiciones de extrema pobreza, pobreza o que sea trabajador independiente en situación de vulnerabilidad. El monto del bono equivaldrá a la suma que represente el $25 \%$ de una UIT.

\section{Proyecto de Ley $5163 / 2020-C R .^{59}$}

a) Denominación: Ley del Impuesto a las Grandes Fortunas.

57. Presentado el 27 de abril del 2020.

58. Proyecto no distingue si el aspecto subjetivo únicamente se circunscribe a los sujetos domiciliados en el país.

59. Presentado el 12 de mayo del 2020. 
b) Contribuyentes: personas naturales domiciliadas en el país cuyos patrimonios superan las 400 UIT.

c) Tasa aplicable:

\begin{tabular}{l|c}
\hline Patrimonio neto & Tasa \\
\hline Hasta 400 UIT & 0 \\
\hline Por el exceso de 400 UIT hasta 700 UIT & $1 \%$ \\
\hline Por el exceso de 700 UIT hasta 1000 UIT & $2 \%$ \\
\hline Por el exceso de 1000 UIT hasta 1300 UIT & $3 \%$ \\
\hline Por el exceso de 1300 UIT hasta 1600 UIT & $4 \%$ \\
\hline Por el exceso de 1600 UIT & $5 \%$
\end{tabular}

d) Base Imponible: conformada por el valor de los activos gravables dentro de los cuales se encuentran los inmuebles, vehículos automotores, acciones y bonos, depósitos bancarios, objetos de colección, obras de arte y joyas cuyo valor supere el equivalente a dos UIT, más otros títulos financieros que establezca el reglamento.

Al valor de los activos antes referidos se les deducirán los créditos existentes al 1 de enero del año al que corresponda la obligación tributaria. Asimismo, se admite la posibilidad de deducir los pasivos asociados a los activos anteriormente señalados según se establezca en el reglamento.

e) Aspecto Territorial: no se señala, por lo que se entiende que no existe diferencia en cuanto a la ubicación de los activos gravables.

f) Aspecto Temporal: Permanente.

g) Exposición de Motivos:

(i) El dinero generado por el impuesto será destinado a la satisfacción del ejercicio de los derechos económicos, sociales y culturales. (ii) Se busca reducir los niveles de desigualdad en el país.

(iii) El Perú tiene las tasas de desigualdad y de concentración patrimonial más altas de América Latina.

Cabe indicar que el proyecto de ley dispone la creación de un padrón de riqueza que registre la información contenida en las declaraciones juradas patrimoniales de cada contribuyente. Dicho padrón se encontrará a cargo de la Administración Tributaria.

\section{Proyecto de Ley $6615 / 2020-C R .{ }^{60}$}

a) Denominación: Impuesto de Solidaridad Sobre la Fortuna.

b) Contribuyentes: personas naturales, sociedades conyugales y sucesiones intestadas domiciliadas en el país que posean un patrimonio neto mayor a 250 UIT. En el caso de sociedades conyugales el patrimonio neto debe ser mayor a 500 UIT.

c) Tasas aplicables:

\begin{tabular}{l|c|c}
\multicolumn{2}{l|}{$\begin{array}{c}\text { Tramos } \\
\text { Hasta 250 UIT }\end{array}$} \\
\hline Más de 250 UIT & Hasta 500 UIT & $0.5 \%$ \\
\hline Más de 500 UIT & Hasta 750 UIT & $1 \%$ \\
\hline Más de 750 UIT & Hasta 1000 UIT & $2 \%$ \\
\hline Más de 1250 UIT & Hasta 1500 UIT & $3 \%$ \\
\hline Más de 1500 UIT & & $4 \%$
\end{tabular}

d) Base Imponible: estará constituida por el valor de mercado de los bienes inmuebles con excepción de la casa habitación, vehículos automotores, embarcaciones de recreo, obras de arte, depósitos bancarios, inversiones en acciones o participaciones.

e) Aspecto Territorial: proyecto no hace distinción sobre la fuente o ubicación del patrimonio a gravar. 
f) Aspecto Temporal: permanente.

g) Exposición de Motivos:

(i) OXFAM ha señalado que en el Perú, la reducción de las brechas de desigualdad en el campo social y laboral se encuentra estancada desde el año 2014. Asimismo, se afirma que el sistema tributario se ha tornado más inequitativo y regresivo, pues pagan más quienes menos tienen.

(ii) La creación de un impuesto solidario a la riqueza busca una distribución más adecuada de los ingresos y una legislación tributaria más justa que no castiga a quienes tienen menos recursos.

\section{Nuestros comentarios y/o recomendacio- nes sobre los proyectos presentados.}

Resulta innegable, en todo sentido, que en nuestro país existe desigualdad en lo que respecta a la distribución de riqueza.

Al margen de que resulte discutible si esa desigualdad pueda ser combatida con la imposición de mayores gravámenes a los contribuyentes y no a través de políticas de formalización que coadyuven a generar una ampliación de la base tributaria, o generar una mayor eficiencia en la administración de los recursos por parte del Estado; en esta sección brindaremos comentarios generales en relación a los proyectos de ley existentes en el Congreso de la República que buscan crear un Impuesto a la Riqueza:

a) Con respecto al Impuesto Solidario a las Grandes Fortunas:

(i) No se establece la posibilidad de deducciones a la base, con lo cual se puede ver perjudicada la capacidad contributiva de las personas.

(ii) Como contribuyente del impuesto se incorpora a la figura del grupo económico. Sin embargo, se inobserva que este concepto carece de perso- nería jurídica; por lo que su tributación devendría en impracticable.

(iii) Se grava a las personas jurídicas, lo cual puede generar un efecto no deseado. Efectivamente, recordemos que las cargas impositivas usualmente son trasladadas por las empresas al consumidor final, vía el incremento en los precios de venta. En ese sentido, la imposición de este gravamen podría generar un alza de precios al consumidor. En todo caso, si se incorporan a las personas jurídicas, deberían de excluirse de las personas naturales el valor de las acciones que éstas posean a efectos de evitar una doble imposición.

(iv) El impuesto está diseñado para gravar los ingresos superiores a S/ $1,000,000.00$ en el caso de personas naturales y $S / 10,000,000.00$ para el caso de las personas jurídicas; inobservando que ya existe el impuesto a la renta que grava la misma manifestación de capacidad contributiva.

(v) No se hace referencia al momento en que nace la obligación tributaria ni la fuente de los ingresos o la ubicación de los inmuebles sujetos al gravamen.

(vi) No se establecen mínimos exentos ni supuestos de inmuebles no gravados, como la casa habitación lo cual inobserva las recomendaciones efectuadas por la CIAT sobre el particular.

b) Con respecto al Impuesto a las Ganancias:

(i) El proyecto señala que la naturaleza del impuesto sería temporal —por los ejercicios 2020 y $2021-$ y su periodicidad anual. Tal disposición, desconoce el hecho de que los tributos de periodicidad anual - para que puedan ser aplicables - tienen que ser aprobados antes del ejercicio en el cual pretenden entrar en vigencia. Por tanto, si se buscaba la vigencia del mismo para el presente ejercicio 2021, el proyecto 
debió de convertirse en ley antes del 01 de enero del 2021.61

(ii) Al igual que en el caso el Impuesto Solidario a las Grandes Fortunas, se genera una doble imposición al gravar hechos ya contemplados en el ámbito de aplicación del impuesto a la renta.

(iii) Se comete el mismo error de gravar a las personas jurídicas con los efectos ya mencionados.

c) Con respecto al Impuesto a las Grandes Fortunas:

(i) Se grava el patrimonio neto desde una suma superior a los 400 UIT $^{62}$, con lo cual claramente el impuesto resultaría aplicable a la mayoría de personas que son de clase media alta sin que ello implique que se trate de personas que posean fortunas en términos estrictos de la palabra.

(ii) La tasa más alta del proyecto es de $5 \%$, lo cual la convertiría en una de las tasas más altas del mundo en comparación con los países que aún aplican este tipo de impuestos. Ello podría representar un cuestionamiento relativo a la capacidad contributiva de los sujetos pasivos.

(iii) En cuanto a los activos a ser gravados por el impuesto, el proyecto dispone que el mismo será de aplicación a otros títulos financieros que establezca el reglamento, lo cual claramente viola el principio de reserva de ley, por tratarse de una norma relativa al aspecto objetivo de la hipótesis de incidencia. Recordemos que el Tribunal Constitucional admite este tipo de delegaciones siempre y cuando la norma con rango de ley haya establecido los parámetros para tal desarrollo; lo cual no sucede en el presente caso. (iv) Resulta altamente cuestionable el hecho de que se disponga la creación de un padrón de riqueza administrado por la Administración Tributaria, en donde se tenga que consignar, por ejemplo, el detalle de las joyas de uso personal cuyo valor - ¿de mercado?supere las dos UIT.

(v) No se establecen mínimos exentos ni supuestos de inmuebles no gravados como la casa habitación.

d) Con respecto al Impuesto de Solidaridad sobre la Fortuna:

(i) De acuerdo con el presente proyecto, se entenderá que una persona natural posee una fortuna $-y$ por lo tanto, se encontrará afecto- cuando su patrimonio neto sea mayor a 250 UIT, es decir aproximadamente unos USD 303,000.00; con lo cual se gravaría a la gran mayoría de la clase media en el país.

(ii) En la fórmula de la escala progresiva acumulativa, existe un error al haberse omitido la franja que va desde los 1,000 a 1,250 UIT que no tiene una tasa aplicable.

Como se puede observar existen serias falencias e inobservancias a los proyectos de ley presentados. Dado lo anterior, nos permitimos brindar algunas recomendaciones:

a) Se debe tener claro si lo que se desea es crear un impuesto que grave el patrimonio o la riqueza de las personas. En función a ello, se debe establecer la fórmula legal aplicable -mínimos exentos, activos no gravados, entre otros-.

b) En relación con la valuación de los bienes que conformarán la base imponible, se tie-

61. Cabe indicar que este proyecto fue presentado en el ejercicio 2020 y tenía como propósito entrar en vigencia en dicho ejercicio.

62. Para el ejercicio $2021, \mathrm{~S} / 1,760,000$. 
ne que ésta debería realizarse a valores de mercado, y no por su valor o costo histórico; ya que tales valores no representan la verdadera capacidad de pago del contribuyente. Sobre este punto, debemos mencionar que ningún proyecto ha abordado claramente la metodología que se aplicará para la determinación del valor de los activos materia de gravamen.

c) No resulta recomendable configurar como sujeto de gravamen a las personas jurídicas, por los efectos que ello puede tener a la economía a través del aumento de precios al consumidor.

d) En caso se intente gravar el patrimonio global, resultará recomendable establecer un mecanismo de crédito para evitar la doble imposición. En ese sentido, ninguno de los proyectos ha sido capaz de abordar esta posible problemática.

e) Algunos de los proyectos de ley presentados establecen el destino que tendrán los montos recaudados - para el otorgamiento de un bono universal, por ejemplo- . Sin embargo, tal disposición contraviene lo dispuesto por el artículo 79 de la Constitución Política del Perú, el cual dispone que el Congreso de la República no puede aprobar tributos con fines predeterminados, salvo por solicitud del Poder Ejecutivo, lo cual no sucede en el presente caso.

f) Finalmente, recomendamos incorporar como mecanismo para evitar la doble imposición un sistema de créditos respecto del impuesto pagado por concepto de predial y vehicular.

Recordemos que hoy existen esos dos impuestos que gravan el patrimonio a nivel de gobierno municipal. En vista de que el tributo propuesto sería un impuesto del gobierno central, -lo que generaría una doble imposición-, el mecanismo anteriormente señalado podría eliminar la eventual doble carga tributaria.

\section{CONCLUSIONES}

El Impuesto a la Riqueza no resulta novedoso en el sistema jurídico peruano, pues ya se encontraba vigente antes de la reforma tributaria llevada a cabo a inicios de la década de los noventa del siglo pasado.

A pesar de lo que se busca con este tipo de gravámenes ${ }^{63}$-el incremento en la recaudación dado el contexto de pandemia-, existe evidencia empírica en términos de legislación comparada, que demuestran que la recaudación asociada no resulta material.

Los países económicamente desarrollados han ido renunciando a la aplicación de este tipo de gravámenes por los problemas que su existencia implicaban, siendo que en Sudamérica se está desarrollando el fenómeno a la inversa.

En los proyectos de ley presentados ante el Congreso de la República se denotan serias falencias u omisiones que deberían ser subsanadas, con miras a que no se planteen acciones de inconstitucionalidad, una vez que los mismos se incorporen al sistema jurídico doméstico.

Finalmente, se puede observar que la mayoría de los proyectos presentados se encuentran enfocados en gravar a la clase media del país, no siendo su objetivo aquellos sujetos que realmente poseen altos niveles de patrimonio personal; para lo cual por ejemplo se podrían tomar en consideración variables tales como aquellas contenidas en la ENAHO —Encuesta Nacional de Hogares - realizada por el RENIEC o la propia base de datos de la Administración Tributaria respecto a la calificación que posee de todos los contribuyentes - Principales Contribuyentes nacionales, por ejemplo-.

63. De acuerdo a lo observado en las exposiciones de motivos que acompañan a los cuatro proyectos de ley comentados. 